\title{
Repensar o Currículo como Emancipador
}

Jesus Maria Sousa ${ }^{1}$

\section{Resumo}

Se é certo que os estudos curriculares tiveram o condão de, a partir da análise crítica, chamar a atenção para os conhecimentos veiculados pelo currículo, acusando-o de indutor de desigualdades sociais, também é certo que tal facto nos deixou a nós, estudiosos do currículo, num impasse relativamente à função da escola, trazendo à discussão o tipo de conhecimento que ela deve valorizar: um conhecimento experiencial, de senso comum, circunscrito às mundividências dos alunos, ou um conhecimento mais académico e especializado, mesmo que rotulado de elitista. Esta questão ganha maior significado num contexto de educação de massas, uma vez que a ortodoxia curricular entra em choque com a diversidade cultural, sendo por isso apresentada como castradora na construção de muitas outras identidades pessoais e sociais. Mas num mundo cada vez mais globalizado e altamente competitivo, de mudança acelerada a todos os níveis sob a batuta das tecnologias de informação e comunicação, não poderá o currículo ser efetivamente um instrumento de emancipação?

Palavras-chave: currículo castrador; conhecimento e senso-comum; currículo emancipador 


\section{Rethinking the curriculum as emancipatory}

\section{Repensar el curriculum como emancipador}

Abstract

No one doubts that the curriculum studies had the power, from the critical analysis, to draw the attention onto the knowledge conveyed by the curriculum, accusing it of inducing social inequality. But it is also true that we were left, as curriculum specialists, somewhat paralyzed regarding school function, bringing to discussion the type of knowledge that it should value: either an experiential common sense knowledge, restricted to the worldviews of students, or a more academic and expertise knowledge, even if labeled elitist. This issue is particularly meaningful in a mass education context, since the curriculum orthodoxy clashes with cultural diversity and is therefore presented as castrating the construction of many other personal and social identities. But in an increasingly globalized and highly competitive world, of accelerated change at all levels, under the umbrella of information and communication technologies, cannot the curriculum effectively be an instrument of emancipation?

Key-words: castrating curriculum; knowledge and common sense; emancipating curriculum

\section{Resumen}

Si es cierto que los estudios curriculares tenían el poder, a partir del análisis crítico, para llamar la atención sobre el conocimiento transmitido por el currículo, acusándolo de inducir la desigualdad social, también es cierto que nos ha dejado, como especialistas en currículo, un tanto paralizados con respecto a la función de la escuela, trayendo a la discusión del tipo de conocimiento que se debe valorar: un conocimiento de sentido común experiencial, restringido a las visiones del mundo de los estudiantes, o un conocimiento más académico, incluso si la etiqueta elitista. Este problema adquiere mayor importancia en un contexto de educación de masas, ya que la ortodoxia del currículo choca contra la diversidad cultural y por lo tanto se presenta como castradora de la construcción de muchas otras identidades personales y sociales. Pero en un mundo cada vez más globalizado y altamente competitivo, de cambio acelerado en todos los niveles bajo la batuta de tecnologías de la información y comunicación, no puede el currículo ser efectivamente un instrumento de emancipación?

Palabras clave: currículo castrador; conocimiento y sentido común; currículo emancipador. 


\section{Introdução}

Tendo sido formada, enquanto professora de ensino básico $^{1}$, para a execução meticulosa de programas de disciplinas, assente na definição prévia de objetivos gerais e específicos, categorizados em objetivos cognitivos (BLOOM et alli, 1956), afetivos (KRATWOHL, 1972), e psicomotores (HARROW, 1972), e desdobrados em comportamentais e operacionais (MAGER, 1976; 1977; 1979), com menção clara e explícita à ação final e observável do aluno, à condição em que tal ação deveria ser demonstrada e ao critério mensurável que determinasse à partida se tais objetivos tinham ou não sido atingidos, e em caso positivo, em que grau, o meu conceito de currículo era simplesmente o do desenvolvimento curricular, sem qualquer tipo de questionamento social, político ou mesmo epistemológico.

A autonomia que me era "concedida" restringia-se apenas à diversificação metodológica que eu conseguia pôr ao serviço desses mesmos objetivos, na senda dos autores fundacionais do campo dos estudos curriculares que colocavam a tónica nos meios para se atingirem os fins, na lógica da racionalidade instrumental processo-produto que caracterizava este modelo curricular (tecnológico), em consonância, aliás, com o ambiente fabril que se vivia na revolução industrial.

"A educação é um processo de moldagem, tanto quanto a manufatura de carris de aço", afirmava Bobbitt (1918, p. 259), num contexto de expansão das linhas férreas, demonstrando a sua crença na aplicação generalizada dos princípios tayloristas então recentemente lançados (TAYLOR, 1911) a diversas esferas de ação, incluindo a da educação. A formação de mão-de-obra disciplinada, para trabalhar nas fábricas, necessitava assim do apoio incondicional de uma escola de massas, uma escola pública, através de um currículo prescritivo, rígido e ortodoxo. Nesta arquitetura, ao professor cabia a execução de um plano linear e progressivo, sequenciado do mais simples ao mais complexo, exteriormente determinado, conforme as seguintes definições de currículo:

1. "[The curriculum is] all the learning experiences planned and directed by the school to attain its educational goals" (TYLER, 1957, p. 79);
2. "Curriculum is a sequence of content units arranged in such a way that the learning of each unit may be accomplished as a single act, provided the capabilities described by specified prior units (in the sequence) have already been mastered by the learner" (GAGNÉ, 1967, p. 23);

3. "[Curriculum is] all planned learning outcomes for which the school is responsible" (POPHAM; BAKER, 1970, p. 48).

Uma "gestão científica" do ensino, à semelhança da gestão científica taylorista, não poderia tolerar a transgressão da ordem estipulada, por colocar em causa a rendibilidade desejada. O professor teria assim um papel de técnico de ensino, zelando para que a engrenagem fosse devidamente oleada em prol da eficácia e produtividade do sistema, visando o máximo de resultados com o mínimo de recursos.

Fui assim formada e, enquanto orientadora de estágio e orientadora pedagógica, formei alguns professores de Inglês como Língua Estrangeira para o controlo doseado do tempo ao longo da unidade letiva, para a organização do espaço da sala de aula, para a utilização eficaz dos recursos tecnológicos, para a diversificação das estratégias de ensino tendo em conta os objetivos comportamentais, para a motivação e disciplina dos alunos, tal como os formei para evitar os chamados tempos mortos e a lidar com situações imprevistas. Fui formada e formei para o cumprimento ortodoxo de um currículo prescritivo e didactizado, que pouco ou nenhum espaço me oferecia para me assumir como verdadeira profissional de educação.

\section{As teses do currículo castrador}

Por isso, foi com entusiasmo idealista que aderi à mudança de foco nas preocupações pedagógicas do "como ensinar" (currículo didactizado) para "ensinar o quê" (currículo epistemológico), mudança essa desencadeada pelas reflexões e análises críticas sobre o papel da escola enquanto reprodutora de desigualdades sociais, com origem na discussão generalizada sobre temas sociais relevantes levada a cabo pela Escola de Frankfurt ainda nos anos trinta do século XX. 
Ao contrário do ideal iluminista que presidira à instauração da escola pública - o de retirar o povo das trevas da ignorância - a reflexão trazida por Althusser (1970) sobre essa mesma escola enquanto um dos aparelhos ideológicos do Estado, em relação direta com a economia e a produção, bem como as análises sociológicas de Bourdieu e Passeron (1970), sobre La réproduction social através do habitus e da (dupla) violência simbólica relativamente a determinado capital cultural, exercida na École capitaliste en France (BAUDELOT; ESTABLET, 1971), e através da Schooling in capitalist America (BOWLES; GINTIS, 1976), obras estas publicadas nos anos setenta do século que passou, trouxeram um novo olhar, já menos ingénuo, sobre aquilo que efetivamente se ensinava e se aprendia na escola, numa perspetiva de poder, na arena política entre dominantes e dominados.

Não nos esqueçamos do ambiente fértil para a reflexão, nomeadamente quando os estudos sociais em escolas e universidades passaram a ganhar uma dimensão mais afirmativa e de intervenção política, na senda dos movimentos de protesto da década de $60^{2}$, de que os acontecimentos de maio de 68 foram paradigmáticos, como bem descreve Ardoino (1973):

\footnotetext{
“la spontanéité du groupe en liberté, la libération de la parole séculairement confisquée, la "débâcle" de l'affectivité, la contestation des figures paternelles, la coïncidence de la revendication politique avec la réapparition d'une imagination exubérante et d'un goût intense pour la création auraient pu constituer des invites à la réflexion" (ARDOINO, 1973, p. 433).
}

Quebradas as amarras da tradição, por um processo revolucionário de pensamento que punha a tónica na liberdade, todas as esferas da vida social foram sacudidas por reflexões teóricas inspiradas em luta de classes, pondo em questão a ordem social, educacional, escolar e até mesmo curricular. Eram de facto extremamente apelativas e sedutoras as teorias críticas que nos levavam a desconfiar do status quo, fosse ele político, económico, cultural, ou social num sentido mais amplo. E com o currículo não foi diferente.
Como diz Silva (2000), "As teorias tradicionais eram teorias de aceitação, ajuste e adaptação. As teorias críticas são teorias da desconfiança, questionamento e transformação radical" (p. 27). Isto é, enquanto as teorias tradicionais consagravam a ortodoxia, com o receituário didático-pedagógico das regras de bem ensinar, as teorias críticas, por serem transgressoras, provocaram a reconceptualização do currículo, enquanto área de estudo e investigação que se encontrava ainda a dar os primeiros passos como tal.

Pinar (2010) explica bem como, quase por acaso, se deu esta viragem na I Conferência realizada na Universidade de Rochester, em 1973, acabando por marcar o início do movimento da Reconceptualização Curricular:

\begin{abstract}
"My PhD mentor, Paul R. Klohr, and I had planned the 1973 Rochester Conference as a "state-of-the field" meeting; we did not foresee that it would initiate a decade of dispute that would result in the field mapped in Understanding Curriculum" (PINAR et alli, 1995) (PINAR, 2010: 528).
\end{abstract}

Começou assim a ser forjada uma nova identidade no campo dos estudos curriculares ainda emergentes, assistindo-se à passagem do "curriculum development" para a compreensão do próprio currículo ("understanding curriculum"), não só do currículo explícito, formal e oficial, mas também do currículo real, aquilo que acontecia na escola, ou fora dela, mas por sua iniciativa, abrangendo igualmente a compreensão do currículo oculto, a operar ao nível do inconsciente, através de mensagens veiculadas de maneira sub-reptícia e insidiosa pela organização e pelas práticas do dia-a-dia da escola, sendo por isso mais difíceis de desconstruir.

Vingava assim a ideia de que o currículo estaria ao serviço de determinada agenda política e ideológica a partir da construção de identidades para posições diferentes a ocupar na sociedade: para papéis de submissão e subordinação, no caso dos filhos das classes trabalhadoras, e para papéis de controlo e liderança, no caso dos filhos das classes detentoras dos meios de produção. 
Esta narrativa (neo)marxista de manutenção das diferenciações de classe social e económica, através do currículo, foi entretanto alargada para outro tipo de diferenciação social trazida pelo debate pós-moderno: a da raça, da cor da pele, do género e da orientação sexual de cada um, quando confrontados com o conhecimento que a escola pública veicula através de um currículo exclusivamente desenhado a partir de uma única referência: o modelo europeu de cultura e civilização, espartilhado em áreas autónomas e especializadas, fortemente denunciado pelo movimento dos "estudos culturais", sob a liderança de Giroux e Simon (1989).

Sobre o currículo pende agora a crítica de um cada vez maior desfasamento entre as tradições modernistas que o enformam desde o nascimento da escola pública, enquanto agência de "governamentalização" da ordem social, e as reais condições pós-modernas que vivemos atualmente. Temos assim um currículo ortodoxo, onde a questão da identidade cultural se joga no âmbito das certezas e dos valores ocidentais do homem branco, de estatuto social elevado, saudável, heterossexual, com hábitos urbanos, e de um determinado Estado (SOUSA, 2015), como verdades universais, em confronto direto com um mundo pós-moderno de identidades híbridas, práticas culturais locais e espaços públicos plurais, que surgem como ameaçadores, como explicava Giroux em 1994, num dos seus artigos online:

"an epistemic arrogance and faith in certainty sanctions pedagogical practices and public spheres in which cultural differences are viewed as threatening; knowledge becomes positioned in the curricula as an object of mastery and control; the individual student is privileged as a unique source of agency irrespective of iniquitous relations of power; the technology and culture of the book is treated as the embodiment of modernist high learning and the only legitimate object of pedagogy" (GIROUX, 1994).

Torres Santomé (1998) elenca mesmo algumas "vozes ausentes na seleção da cultura escolar" (p. 131) que acabam por ficar esmagadas pela cultura hegemónica:

- As culturas infantis e juvenis;
- As culturas das etnias minoritárias ou sem poder;

- As culturas do mundo feminino;

- As culturas das sexualidades lésbica e homossexual;

- As culturas da classe trabalhadora e das pessoas pobres;

- As culturas do mundo rural e ribeirinho;

- As culturas das pessoas portadoras de deficiências físicas e/ou psíquicas;

- As culturas da terceira idade;

- As culturas do Terceiro Mundo.

São estas vozes heterogéneas que não são contempladas pelo currículo, apesar de povoarem a escola pública e nela acentuarem cada vez mais as cores da diferença. Por isso se diz que o currículo é castrador, quando as ignora, subordinando-as aos ditames de uma história única e cultura estandardizada, num processo de "testing, sorting and tracking".

\section{O conhecimento como cerne do currículo}

Como estamos a ver, o que move os estudos curriculares, no momento atual, é a sua própria essência, aquilo que está no âmago do currículo, ou seja, o conhecimento. É o conhecimento afinal que justifica a existência da escola, da universidade ou de outra instituição educativa. Só que a abordagem ao conhecimento tem variado ao longo da história da epistemologia: ou se considera que o conhecimento tem existência própria, estando apenas à espera de ser descoberto; ou se considera que o conhecimento é uma realidade construída pelo sujeito.

Na primeira hipótese, cabe ao currículo propiciar o acesso ao conhecimento, por uma via racional ou empírica. Pela via racional, partindo do princípio de que o conhecimento está dentro de cada um, sendo necessário apenas desvelá-lo, através do raciocínio silogístico, das inferências lógico-matemáticas, conduzidas pelo professor 
socrático como parteiro das ideias do aprendiz, sendo a matemática e a lógica disciplinas fundamentais neste processo. Pela via empirista, através da observação e da experimentação com base nos sentidos, muitas vezes falíveis, é certo, recorrendo por isso à instrumentação (microscópios ou telescópios enquanto extensões mais refinadas dos sentidos humanos) para obviar às relatividades da percepção.

Quando se começa a falar de conhecimento científico, ele surge como resultado de múltiplas observações descomprometidas e sistemáticas; seria um conhecimento objetivo, sem qualquer interferência de valores humanos ou religiosos. À incerteza da razão entregue a si própria, opõe-se, como vemos, a certeza da experiência, ordenada por etapas bem definidas: 1. Identificação do problema; 2. Formulação de uma hipótese; 3. Recolha de dados; 4. Interpretação dos dados recolhidos; 5. Extração de conclusões. 6. Confirmação, rejeição ou modificação da hipótese.

E é no contexto do pensamento científico moderno que nasce a escola pública e, com ela, o currículo científico e tecnológico centrado na organização do acesso ao conhecimento, um conhecimento que ninguém punha em questão, por ser objetivo, factual, observável e mensurável.

Mas é sobre esse conhecimento pressupostamente neutro que as teorias críticas e pós-críticas do currículo questionam, relacionando-o com o poder: Que conhecimento faz parte do currículo? De um universo extremamente vasto, por que motivo determinado conhecimento é considerado mais importante do que outro? Que conhecimento é posto à parte? Quando se fala de conhecimento socialmente válido, ele é válido para quem? Quem o determina? De que classe social é o construtor do currículo? A quem serve essa seleção de conhecimento?

São as questões de desconfiança do "porquê" e "para quê" do conhecimento do currículo, conhecimento esse corporificado em manual escolar de maneira a preservar a sua ortodoxia, que levaram os estudos curriculares a encarar o seu objeto de estudo de outra forma, não podendo deixar de ter como pano de fundo, "La condi- tion postmoderne" (LYOTARD, 1979) que tudo relativiza, levando-nos a olhar para a própria ciência como criação subjetiva e por isso assente em areia movediça, segundo o princípio da falsificabilidade (POPPER, 1984). Lyotard considera a pós-modernidade como o fim das meta-narrativas (master narratives), das verdades absolutas, dos grandes esquemas explicativos do mundo, sejam eles ideologias ou sistemas de saber totalitários, como passa a ser encarada a própria ciência. Se ela foi libertadora, quando surgiu, trazendo a esperança para a resolução dos problemas que assolavam a humanidade, substituindo Deus, a visão anarquista da ciência, segundo Paul Feyerabend (1924-1994) acusa-a de nos impor a todos um único Método, universal, aprisionando-nos numa ditadura presumidamente científica. Seguindo este raciocínio, por que não aceitar as vias alternativas da ciência, como as medicinas alternativas, a dança da chuva ou a astrologia?

Entramos assim na segunda hipótese: a de que o conhecimento é construído pelo sujeito. Uma coisa é o acesso à informação (e esta tem aumentado de forma exponencial com a explosão tecnológica); e outra coisa é a informação ganhar significado para o sujeito, quando é filtrado pelo seu contexto particular de vida, passando a conhecimento. Enquanto antes o sujeito devia se abstrair da sua subjetividade, entendendo-se o "facto" como a própria realidade - ou seja, o conhecimento com existência própria; agora o "facto" é modelado pelas percepções, concepções e representações do sujeito - isto é, o conhecimento é construído pelo sujeito. A dissociação entre sujeito e objeto, formulada por Descartes, ego cogitans e res extensa, dá assim lugar à ideia de sujeito enquanto elemento criador do objeto, aquele que confere significado ao objeto observado. Em última análise, dir-se-ia que não existe conhecimento se não houver o sujeito que o apreende.

É evidente que esta nova visão de conhecimento, enformada pela "condition post-moderne", terá necessariamente os seus reflexos no currículo. Já ninguém tem dúvidas de que, chamemos os nossos tempos de pósmodernidade, modernidade tardia (GIDDENS, 2000), modernidade líquida (BAUMAN, 2006) ou hipermodernidade 
(LIPOVETSKY, 2004), o que acontece é que se vive agora uma nova ordem, relativa e complexa, com implicações na forma como o conhecimento é encarado.

\footnotetext{
“... uma nova ordem, onde com muita dificuldade caberá a divisão simplista e dicotómica, diria que cartesiana, arrumada em razão, por um lado, e emoção, por outro; direita, por um lado, e esquerda, por outro; homem, por um lado, e mulher, por outro; negro, por um lado, e branco, por outro. Pelo contrário, estamos a viver o tempo da mestiçagem ético-filosófica, política e ideológica" (SOUSA, 2009: 3).
}

Estamos a viver a época do fluido, com o esbatimento das fronteiras outrora rígidas entre as diversas disciplinas, entre as ciências físicas e naturais e as ciências humanas e sociais, entre o sujeito que investiga e o objeto investigado, entre o conhecimento científico e o senso comum, entre a cultura elitista e a cultura de massas... Estamos também a viver a época do efémero e do transitório, ao nível do trabalho e emprego, do local de residência, dos interesses e das relações pessoais, bem como a época da incerteza e da indeterminação, sob a égide do relativismo absoluto das chamadas "presunções universalizantes", relativismo esse que dá corpo às teorias pós-críticas do currículo.

E se, no âmbito dos estudos curriculares, parece haver já unanimidade sobre a descentração do currículo do "como" para "o quê", procurando compreender melhor o conhecimento que ele veicula, do ponto de vista da sua relação com a ideologia e o poder, desde as primeiríssimas reflexões críticas sobre a escola ("understanding curriculum"), também é certo que desde então tem restado uma má consciência nos curriculistas sobre, afinal, o porquê do currículo e da escola. E à medida que se levanta o tom da crítica sobre o que efetivamente se ensina e se aprende na escola, demonstrando a sua ligação com o património cultural ocidental que privilegia o capital cultural dos alunos brancos de classe média e alta, vem-se assistindo a uma viragem cada vez mais acentuada para a construção de um currículo com raízes na cultura local, incorporando muitos produtos da chamada cultura popular.

\section{Um currículo emancipador?}

Chegados a este ponto, trago dois pensadores críticos que nos poderão ajudar a refletir sobre o que, à partida, parece um paradoxo: a existência e a operacionalização de um currículo emancipador. É que currículo, simplisticamente ligado a grade curricular, é uma expressão em si mesma portadora de ortodoxia, uma vez que constitui o núcleo do processo institucionalizado de educação, sob a responsabilidade da escola. Mesmo que recorra a eufemismos como currículo alternativo ou currículo flexível, haverá sempre instâncias administrativas, professores e educadores, tarefas a serem cumpridas, salários a serem pagos, horários e avaliações, recursos materiais e instalações, e um sem número de elementos que exigem gastos públicos e uma boa gestão dos investimentos. Com este colete-de-forças, como poderá o currículo ser emancipador então?

Um dos autores a que recorro é Paulo Freire que, contrariamente à visão pessimista da reprodução social, por via de um determinismo fatalista operado na escola, acreditou na "Educação como prática de liberdade" (1967), aliando valores da filosofia cristã à dialética hegeliana e ao materialismo histórico. Ao utilizar a alfabetização como processo de conscientização, Paulo Freire acreditou na vocação ontológica do homem, como Sujeito que age sobre o mundo, e que é capaz de o transformar; por mais ignorante que seja, ou por mais mergulhado que se encontre na "cultura do silêncio", ele, Sujeito, tem a capacidade de olhar para o mundo de uma forma crítica, em encontro "dialógico" com o outro. Desde que detenha os instrumentos necessários e adequados para esse encontro, o Sujeito consegue gradualmente aperceber-se não só da sua realidade pessoal e social, como das contradições aí existentes.

Com as reservas naturais relativamente ao público-alvo em questão, trabalhadores da cana-de-açúcar, adultos e iletrados, em contexto de círculos de leitura após uma jornada de trabalho, considero no entanto que é possível extrair da vivência freireana na educação algumas linhas de força para o currículo. Tal como o processo de conscientização pretendia fornecer ao oprimido os instru- 
mentos necessários de leitura e escrita, tendo em vista a sua própria libertação, penso que é possível, também a escola proporcionar um terreno fértil para uma praxis de construção de conhecimento, assumindo o currículo uma dimensão emancipadora associada a um projeto de formação de sujeitos capazes de, conscientemente, refletir, produzir e transformar a sua existência e a do seu meio. Apesar de reconhecer que é difícil de conciliar a problematização sistemática em torno das ideias geradoras, característica da alfabetização freireana, com o currículo que pela sua natureza é ortodoxo, estou convencida de que é possível propiciar a transgressão no âmbito da ortodoxia, desde que contemos com profissionais à altura, com um nível de conhecimento elevado e que detenham ao mesmo tempo uma visão crítica e situada no contexto global da pós-modernidade.

Recorro também a Michael Young, um dos fundadores do movimento da Nova Sociologia da Educação (NSE), que havia publicado, em 1971, um livro significativamente intitulado de "Knowledge and Control: New Directions in the Sociology of Education", constituído por capítulos escritos por si e por outros, como Bourdieu e Bernstein, por exemplo, quando, num rebate de consciência faz o seu mea culpa, raciocinando em torno precisamente de "Bringing Knowledge Back In" (2008), traduzido para Português, em 2010, como "Conhecimento e Currículo. Do socioconstrutivismo ao realismo social na sociologia da educação". Apesar de reconhecer que o conhecimento é socialmente produzido, Young acaba neste livro por defender a sua independência relativamente às lutas de poder e aos interesses sociais, distinguindo claramente o conhecimento académico daquilo que é meramente senso comum, oriundo das experiências do dia-a-dia. Acusa também o relativismo das teorias críticas e pós-críticas, pelo facto de, ao promoverem o discurso das vozes referido no ponto no 1 desta reflexão, nos terem conduzido a um beco sem saída, quando eleva o senso comum à categoria de conhecimento, na presunção de que "todas as afirmações de conhecimento e de verdade são equivalentes, quer derivem do senso comum, da tradição popular, da investigação científica realizada em laboratório ou do conhecimento disciplinar sistemático" (YOUNG, 2010, p. 38)
Considera, pelo contrário, que"é preciso salientar veementemente a desonestidade intelectual dos teorizadores do discurso das vozes e o dano potencial que podem causar àqueles que se encontram nas situações mais vulneráveis" (Id. Ibid. p. 53), para rebater a tese que classifica o conhecimento académico como elitista e ideológico, o que, na sua opinião, revela um profundo anti-intelectualismo. Mesmo que organizado em disciplinas, reforça o autor, o conhecimento académico não é um dado adquirido, mas antes um produto social, pois também ele foi construído, só que neste caso pela comunidade de especialistas e pela própria ciência. Naturalmente que outras questões poderiam aqui ser desencadeadas, trazendo o discurso das vozes à discussão: E quem são os especialistas? Qual a sua visão de mundo? Onde estão localizados os centros de investigação? Quem apoia a ciência? Quais as revistas científicas? Paga-se para nelas se publicar? Etc., etc.

Enfim, sem querer desvalorizar a importância de se analisar, de forma crítica, o currículo (prescritivo e ortodoxo) e o conhecimento académico por ele veiculado nas suas relações com o poder instalado, penso que é importante, também, encará-lo noutra perspetiva, como a sugerida por Freire e Young: a do empoderamento dos aprendizes, precisamente daqueles oriundos dos grupos sociais menos favorecidos. A não ser assim, que instrumentos de promoção social e cultural estará a escola a propiciar a estes grupos, se os relegarmos aos seus saberes práticos vivenciados no seu dia-a-dia?

Considero que é importante dar voz às diversas mundividências que coabitam o palco escolar, mas precisamente para delas partir para a construção do conhecimento de cada um, cabendo à escola pública a responsabilidade de estabelecer a ponte entre esse discurso popular, baseado no imediato e no concreto, e proveniente das experiências quotidianas dos alunos, e o discurso académico. Sem renegar as origens populares, preservando-as antes orgulhosamente dentro de si, o currículo tem a missão de abrir horizontes aos alunos. Por isso, não pode deixar que o senso comum se sobreponha ao conhecimento, numa lógica de aceitação plural e democrática, pois sairão prejudicados precisamente os mais vulneráveis, mesmo que a intenção tivesse sido a de os proteger. 
Em jeito de conclusão, direi que o currículo não pode abdicar de promover o crescimento global, e particularmente intelectual, para que cada aluno, independentemente da sua cor, raça, classe social, género e orientação sexual, tenha a possibilidade de exercitar o pensamento científico de forma a conseguir estar em pé de igualdade com os demais. Para compreender e intervir criticamente no mundo natural e social, é necessário, por isso, um currículo, por natureza ortodoxo, exigente e, por via dessa exigência, emancipador, que lhe permita, com bases sustentadas em conhecimento digno desse nome, a transgressão consciente.

\section{Notas}

1 Iniciei a minha carreira docente no $2^{\circ}$ ciclo do Ensino Básico $\left(5^{\circ}\right.$ e $6^{\circ}$ anos de escolaridade) a lecionar as disciplinas de Inglês e Português.

2 Movimentos a favor da independência das colónias europeias, protestos contra a guerra no Vietname, realização do Woodstock, circulação de músicas de protesto, com Bob Dylan e Joan Baez, por exemplo, afirmação de movimentos feministas, movimentos de resistência contra todas as formas de ditaduras, etc.

\section{Referências}

ALTHUSSER, Louis. Aparelhos ideológicos de Estado. Rio de Janeiro: Graal, 1983.

ARDOINO, Jacques. Évolution de la relation pédagogique. Actes du Vle Congrès International des Sciences de l'Éducation: L'apport des Sciences Fondamentales aux Sciences de I'Éducation (tome 2). Paris: E.P.I., 1973, pp. 431-439.

BAUDELOT, Christian; ESTABLET, Roger. L'école capitaliste en France. Paris: PUF, 1971.

BLOOM, Benjamin S. et alli. Taxonomy of educational objectives. New York: Longmans, 1956.

BOBBIT, John Franklin. The curriculum. Boston: Houghton Mifflin, 1918.

BOURDIEU, Pierre; PASSERON, Jean-Claude. La reproduction. Éléments pour une théorie du système d'enseignement. Paris : Éditions Minuit, 1970.

BOWLES, Samuel; GINTIS, Herbert. Schooling in capitalist America. New York: Basic Books, Inc., Publishers, 1976.
FREIRE, Paulo. Education as the practice of freedom in education for critical consciousness. New York: Continuum, 1973.

GAGNÉ, Robert W. Curriculum research and the promotion of learning. In R. W. TYLER; R. M. GAGNÉ; M. SCRIVEN (Eds.). Perspectives of curricular evaluation. Chicago: Rand McNally, 1967.

GIDDENS, Anthony. The consequences of modernity. Oeiras: Celta Editora, 2000.

GIROUX, Henry. Slacking Off: Border Youth and Postmodern Education. Journal of Advanced Composition 14:2 (Fall 1994), 1994, pp. 347-366,

GIROUX, Henry; SIMON, Roger. Popular culture, schooling, and everyday life. Granby, Mass.: Bergin \& Garvey, 1989.

HARROW, Anita J. A taxonomy of the psychomotor domain. New York: David McKay Comp., 1972.

KRATWOHL, David R. Taxonomy of educational objectives: Handbook II. Affective domain. New York: David McKay Co., Inc., 1964.

LIPOVETSKY, Gilles. The hypermodern times. Paris: Grasset Editor, 2004.

LYOTARD, Jean-François. The Postmodern Condition. A Report on Knowledge. Manchester: Manchester University Press, 1984 (Ed. Orig. 1979).

MAGER, Robert F. A formulação de objetivos de ensino. Porto Alegre: Globo, 1976.

Medindo os objetivos de ensino. Porto Alegre: Globo, 1977. Globo, 1979.

Análise e problemas de desempenho. Porto Alegre:

PINAR, William F. The reconceptualization of curriculum studies. Journal of Curriculum Studies, 10 (3), 1978, pp. 205-214.

The next moment. In E. MALEWSKI (Ed.). Curriculum

Studies Handbook. The next moment. s.l.: Taylor \& Francis, 2010, pp. 528-533.

POPHAM, W. James; BAKER, Eva. Systematic instruction. Englewood Cliffs, NJ: Prentice Hall, 1970.

POPPER, Karl. The Open Universe: An Argument for Indeterminism. Paris: Hermann, Éditeur des Sciences et des Arts, 1984.

SILVA, Tomaz Tadeu da. Teorias do Currículo. Uma introdução crítica. Porto: Porto Editora, 2000.

SOUSA, Jesus Maria. "The University of Madeira as a rotating platform of research and higher education in the world". 2009. Disponível em http://www.uma.pt/jesussousa/. Acesso em 04-02-2016. 
. O currículo e a identidade cultural. In J. C. MORGADO; G. L. MENDES; A. F. MOREIRA; J. A. PACHECO (Eds.), Currículo, internacionalização e cosmopolitismo (Vol. 1), Santo Tirso: De Facto Editores, 2015, pp. 171 -178.

TAYLOR, Frederick. Principles of Scientific Management. Easton: Hive, 1911.

TORRES SANTOMÉ, Jurjo. (1998). Globalização e Interdisciplinariedade. O currículo integrado. Porto Alegre: Artmed Editora, 1998.

TYLER, Ralph W. The curriculum then and now. In Proceedings of the 1956 Invitational Conference on Testing Problems. Princeton, NJ: Educational Testing Service, 1957.

YOUNG, Michael. Conhecimento e Currículo. Do socioconstrutivismo ao realismo social na sociologia da educação. Porto: Porto Editora, 2010.

(Ed.). Knowledge and Control: New Directions in the Sociology of Education. London: Collier-Macmillan, 1971.

Recebido em 16 de janeiro de 2016.

Aceito em 25 de fevereiro de 2016. 